\title{
A Discriminação Certificada: 0 Discurso da Revista Você S.A. sobre a Obrigatoriedade da Pós-Graduação para Inserção no Mercado de Trabalho.
}

Recebido em 19.05.2014. Aprovado em 11.04.2015

Avaliado pelo sistema double blind review DOI: http://dx.doi.org/10.12712/rpca.v9i1.450

\section{Marcelo Almeida de Carvalho Silva}

marceloacs@hotmail.com

Pontifícia Universidade Católica do Rio de Janeiro - PUC - Rio de Janeiro - RJ - Brasil

\author{
Alessandra de Sá Mello Costa \\ alessandra.costa@iag.puc-rio.br \\ Pontifícia Universidade Católica do Rio de Janeiro - PUC - Rio de Janeiro - RJ - Brasil
}

\section{Ana Heloisa da Costa Lemos}

aheloisa@iag.puc-rio.br

Pontifícia Universidade Católica do Rio de Janeiro - PUC - Rio de Janeiro - RJ - Brasil

\section{Resumo}

A premência do diploma de pós-graduação parece constituir um dos principais discursos sobre as características necessárias para os indivíduos alcançarem o sucesso no mercado de trabalho. Diante desta questão, este estudo se propôs a investigar como ocorre a construção deste discurso analisando a participação de uma importante revista de negócios na sua constituição. Para isso, reportagens da Você S.A. foram coletadas e submetidas à análise crítica do discurso, mais especificamente ao modelo tridimensional de Norman Fairclough (2001). Concluiu-se que, por meio de estratagemas linguísticos, os discursos analisados procuram reforçar a importância da pós-graduação como critério de diferenciação e, consequentemente, de discriminação entre os trabalhadores.

Palavras-Chave: Pós-graduação, certificação, discriminação e discurso.

\begin{abstract}
:
The urgency of the graduate diploma seems to be an important discourse about the characteristics necessary for individuals to achieve success in the labor market. Faced with this question, this study aimed to investigate how is the construction of this speech, analyzing the participation of a major business magazine in its constitution. For this, reports of Você S.A. were collected and submitted to critical discourse analysis (CDA), specifically the three-dimensional model of Norman Fairclough (2001). It was concluded that, through linguistic stratagems, the analyzed discourses seeks to reinforce the importance of graduate as a criterion for differentiation and, consequently, the discrimination between workers.
\end{abstract}

Key-Words: Graduate, certification, discrimination and discourse. 


\section{Marcelo Almeida de Carvalhos Silva, Alessandra de Sá Mello Costa e \\ Ana Heloisa da Costa Lemos}

\section{Introdução}

A relação existente entre escolaridade e obtenção de emprego é quase consensual nos estudos que abordam o tema (LEITE, 1997; FERREIRA, 2000; FERNANDES e MENEZES-FILHO, 2002; BARTALOTTI e MENEZES-FILHO, 2007; LEMOS, DUBEUX e PINTO, 2009). Tal relação pode ser considerada fruto de ambientes competitivos e dinâmicos, onde o processo educacional serve de ferramenta estratégica para a identificação de talentos (KARAWEJCZYK, SILVEIRA, THIEL E VELASQUES, 2012). Corroborando este argumento, Fogaça e Salm (2006, p.42) afirmam que nos anos 1980 e 1990 "os diagnósticos da situação brasileira face às mudanças na economia revelaram um ponto consensual quanto à adequação dos recursos humanos às novas exigências do mercado de trabalho: a centralidade da educação geral". Dessa forma, a educação é considerada como o recurso capaz de fomentar o desenvolvimento socioeconômico e assim potencializar a competitividade das empresas (PAIVA, 1994; MACHADO, 1998). Por este motivo, torna-se senso comum o discurso que postula a qualificação do trabalhador, por meio de sua educação formal, como critério de sua alocação em um mercado que exige trabalhadores mais instruídos e educados (BRAVERMAN, 1987; BARBARA, 1999).

A partir disso, a escolaridade torna-se a panaceia capaz de solucionar os problemas de qualificação da mão-de-obra e, consequentemente, de desenvolvimento econômico. Proclamase, então, a escolaridade do trabalhador como fator relevante para sua inserção no mercado profissional. Por isso, o indivíduo busca qualificar-se por meio da educação formal, para atender as novas exigências do mercado. Este fenômeno ajuda a explicar a tendência mundial de elevação da escolaridade e do consequente aumento da oferta de mão-de-obra escolarizada (LEITE, 1997). Segundo o censo do ensino superior do Instituto Nacional de Estudos e Pesquisas Educacionais (INEP), havia aproximadamente sete milhões de estudantes matriculados em cursos superiores no Brasil em 2012 (INEP, 2013).

Neste sentido, a expansão do ensino superior, ocorrida desde os anos 1960, serviu de base para a expansão da educação em mais um nível: a pós-graduação (CUNHA, 1974). Esse acréscimo permitiu às instituições de ensino a oportunidade de oferecer mais cursos, acrescentando-se, dessa forma, mais um nível educacional ao repertório de opções disponíveis ao indivíduo em busca qualificação. Assim, o retorno dos trabalhadores aos bancos das instituições de ensino é fortalecido pelo apelo a constante atualização do profissional, discurso que advoga a necessidade da pós-graduação (SARAIVA, 2011).

Segundo Karawejczyk et al. (2012), considerando o campo da administração de empresas, a pósgraduação abrange os cursos de Master Business Administration (MBA), cursos in company, educação executiva, mestrado profissional e acadêmico. 0 primeiro é uma qualificação amplamente aceita em gestão e reconhecida no mundo todo (BARUCH e PEIPERL, 2000). No Brasil, o MBA experimentou grande desenvolvimento nos anos 1990, apresentando-se como capaz de, supostamente, impulsionar a carreira (CRUZ e WOOD JR, 2014). Simultaneamente, segundo os autores, estes cursos se consolidaram como produtos para as instituições de ensino, uma "alternativa educacional para formar líderes para as empresas" (CRUZ e WOOD JR, 2014, p. 27). Dessa forma, o MBA é percebido como um passaporte para níveis mais altos na carreira.

Ao mesmo tempo, estas instituições de ensino oferecem também cursos de mestrado acadêmico e profissional. Para Ruas (2003), o mestrado profissional atende a necessidade de formações gerenciais sintonizadas com a complexidade atual do mercado que nem os cursos de especialização, nem os de mestrado acadêmico seriam capazes de atender a essa necessidade. Como resultado, a quantidade de cursos de mestrado profissional em administração aumentou $68 \%$ entre 2006 e 2011, não apenas pelos estímulos orçamentários, mas, sobretudo, "pelo aumento da demanda da sociedade por maior nível de escolarização, que se tornou uma 


\section{A Discriminação Certificada: O Discurso da Revista Você S.A. sobre a Obrigatoriedade da Pós-Graduação para Inserção no Mercado de Trabalho.}

exigência para o ingresso no mercado de trabalho" (CIRANI, SILVA e CAMPANÁRIO, 2012, p.771).

Percebe-se, então, que a construção da escolaridade como ferramenta de desenvolvimento econômico e condição para entrada do indivíduo no mercado de trabalho, não se limita ao ensino superior, mas estende-se ao nível de pós-graduação. Um indicador dessa valorização são as matérias das revistas de negócios que retratam os programas de pós-graduação como um caminho seguro para o sucesso (WOOD JR e PAULA, 2004). Nestas revistas, o MBA - por exemplo - possui um papel dúbio: por um lado é objeto de constantes matérias, por outro, apresenta-se como fonte de receita publicitária (CRUZ e WOOD JR, 2014). Charaudeau (2012), importante pesquisador e analista de discursos publicitários, salienta que tal dualidade pode inclusive comprometer a credibilidade das informações que a mídia presta a sociedade.

Esta linha argumentativa fortalece o questionamento de alguns autores (ver: SALM, 1980; MOTTA, 1986; BRAVERMAN, 1987; MACHADO, 1998; BARBARA, 1999) a respeito do posicionamento ideológico dos que colocam a educação no centro da discussão sobre desenvolvimento econômico e desemprego. Com isto, o discurso que declara a escolaridade como fator condicionante para a entrada e no mercado de trabalho, ganha contornos ideológicos que sugerem que tal discurso pode ter como objetivo atender a interesses específicos.

Parte proeminente na construção deste discurso, as revistas de negócio brasileiras adquirem relevância uma vez que estas oferecem auxílio sobre educação executiva aos leitores por meio de reportagens, propaganda e, em especial, destacando os aspectos utilizados para a construção de rankings com os melhores cursos (CRUZ e WOOD JR, 2014). E neste contexto, Cruz e Wood Jr (2014) destacam a Você S.A. como uma das principais revistas de negócio que tratam do tema da educação executiva no Brasil. Esta questão se torna mais complexa frente aos dados da pesquisa da Associação Nacional de MBA (ANAMBA), cujo resultado indica grande influência do ranking da Você S.A. na escolha sobre onde cursar a pós-graduação.

Partindo desta problematização, este trabalho assume que o caráter imprescindível e inexorável atribuído ao diploma de pós-graduação no Brasil, é fruto de um posicionamento ideológico que ganha materialidade por meio do discurso e, assim, se impregna no tecido social tornando-se senso comum. Deste modo, este artigo propõe-se a discutir a participação da mídia de negócios na construção e disseminação do discurso que coloca a pós-graduação como elemento central para a inserção e ascensão do trabalhador no mercado corporativo.

\section{Referencial teórico}

A compreensão do papel da pós-graduação no Brasil passa, inicialmente, por uma análise da educação universitária. De acordo com Saraiva (2011, p.11), o ensino de administração é permeado por um posicionamento ideológico repleto de "preceitos politicamente embasados". A estrutura pedagógica brasileira é concebida de modo a atender às exigências de qualificação impostas pelas demandas do mercado (MACHADO, 1998; ALVES, 2007). Por isso, as novas referências curriculares devem procurar dotar o trabalhador de conhecimento capaz de atender a cultura específica do novo paradigma tecnológico (MACHADO, 1998). A medida de sucesso para as instituições de ensino passa a ser então a inserção de ex-alunos no mercado de trabalho (SARAIVA, 2011) Por este motivo, o sistema educativo moderno procura apenas produzir alunos empregáveis, adaptados ao mercado e às necessidades da economia (GAULEJAC, 2007).

O uso do termo "produção" torna-se coerente, pois alguns autores apontam um processo de fabricação de administradores no Brasil, na Europa e na Ásia (PARKER e JARY, 1995; STURDY e GABRIEL, 2000 e NICOLINI, 2003). Enquanto Parker e Jary (1995) apontam para um processo de "mcdonalização" das universidades no Reino Unido, Sturdy e Gabriel (2000) indicam um 


\section{Marcelo Almeida de Carvalhos Silva, Alessandra de Sá Mello Costa e \\ Ana Heloisa da Costa Lemos}

processo de mercantilização de MBAs na Malásia, onde as universidades ocidentais disputam mercados de forma similar a uma competição empresarial. Para estes autores, o processo de difusão do conhecimento é considerado um comércio, com alunos tomados como consumidores e cursos de MBA como produtos padronizados, com valor simbólico de status e poder. De acordo com Wood Jr (2013), a crítica ao MBA advém de seu formato comercial hoteleiro que visa aumentar a ocupação das salas de aula para maximizar ganhos.

Considerando também outros tipos de pós-graduação, Saraiva (2011, p.45) afirma que a busca pelo aperfeiçoamento profissional contínuo se justifica sob o ponto de vista econômicofinanceiro, tendo em vista a necessidade das instituições de ensino superior de "manter o fluxo de caixa, de forma que ex-alunos de graduação possam retornar para viabilizar cursos de pósgraduação", incluindo MBAs, cursos de extensão e de mestrados tanto acadêmico quanto profissional. Este último, com aumento no número de cursos oferecidos e de alunos matriculados nos últimos anos (CIRANI et al., 2012), foi objeto de alguns artigos (RUAS, 2003; WOOD JR e PAULA, 2004; FESTINALLI, 2005) indicando que o mestrado profissional possui características de difícil distinção, com tendências de ensino instrumental, voltado a atender aos interesses do mercado empresarial, o que poderia comprometer o conteúdo pedagógico (WOOD JR e PAULA, 2004; FESTINALLI, 2005).

Portanto, percebe-se uma tendência de mercantilização da pós-graduação com o objetivo de atender a demandas específicas das empresas. Cabe ressaltar que a relevância desta questão aumenta se considerarmos o aspecto social, tendo em vista a divergência de interesses entre o mercado e os defensores da democratização da educação (SALM, 1980). 0 autor afirma que o mercado de trabalho estaria interessado em trabalhadores capazes de corresponder às suas expectativas - lucro e geração de riquezas - em oposição aos interesses sociais de democratização da educação. Esta divisão, para o autor, produz um impasse, pois a adequação ao mercado de trabalho requer "um mínimo de educação para a maioria e o máximo para a minoria" (SALM, 1980, p.35). Assim, atender ao mercado significa discriminar o acesso à educação.

Com isso, a dinâmica educacional é instrumentalizada e voltada a atender os interesses do mercado, produzindo trabalhadores supostamente capazes de corresponder tecnicamente às demandas empresariais sem, contudo, desenvolver um aprendizado reflexivo de modo a atender as demandas da sociedade (SARAIVA, 2011). Desta forma, percebe-se um afastamento entre a preparação para o trabalho numa empresa e a preparação do sujeito social, dotado de crítica e emancipado. Nesta mesma linha de raciocínio, Motta (1986, p.47-48) afirma que a educação moderna não se preocupa com o desenvolvimento da pessoa, mas apenas com o desenvolvimento funcional ou profissional, formando "engrenagens [...] e não pessoas adultas, maduras individual e socialmente". As escolas de gestão tornam-se, então, ambientes conservadores e elitistas que fabricam administradores que tenderão a reproduzir modelos e ideologias existentes (NICOLINI, 2003; AKTOUF, 2005).

Contudo, a adequação às demandas empresariais não ocorre apenas no aspecto técnico. Salm (1980, p.51) diz que a escalada hierárquica dentro da estrutura organizacional exige do trabalhador uma "docilidade, submissão, disciplina, responsabilidade, autocontrole, previsibilidade, imaginação" e a escola estrutura-se para formar produtos conforme essa especificação. Sobre isso, Motta (1986) explica que as instituições de ensino voltadas a preparar os candidatos aos cargos inferiores, servem como instrumentos civilizatórios pelos quais a classe dominante pode "domesticar" e dominar os indivíduos das classes dominadas.

A instituição de ensino troca a transmissão de conhecimentos pela transmissão de "atitudes, valores e comportamentos adequados a um bom desempenho nos vários níveis da hierarquia 


\section{A Discriminação Certificada: O Discurso da Revista Você S.A. sobre a Obrigatoriedade da Pós-Graduação para Inserção no Mercado de Trabalho.}

empresarial" (SALM, 1980, p. 51) e as escolas profissionalizantes servem para ensinar como "comportar-se de acordo com os interesses das classes e grupos dominantes" (MOTTA, 1986, p.81). A suposta preparação para o mercado oferecida pelo sistema educacional pode ser vista, então, como uma forma de doutrinar o sujeito a aceitar e se submeter às condições que o mercado de trabalho lhe impõe. As instituições de ensino, a serviço da ideologia capitalista, desempenham um papel habilitador, pois transmitem os saberes técnicos de acordo com as necessidades do sistema produtivo e moralizador, reproduzindo a submissão através da imposição da disciplina (MOTTA, 1986).

Esta submissão, contudo, precisa ser verificada, avaliada e selecionada. Diante desta carência, ganha espaço a certificação como forma de materialização da competência do indivíduo (DELUIZ, 2001). A seleção dos postulantes ao emprego valoriza as credenciais escolares, pois por meio delas é possível identificar os indivíduos mais "docilizados", já que "quem atinge os níveis mais altos do sistema educacional estará dando provas de que se sairá bem no emprego: será mais treinável, aceitará as regras de meritocracia" (SALM, 1980, p.51). 0 certificado confere um privilégio, pois indica que quem o possui é elegível a disputar certo grupo de ocupações, "assegurando-lhe a posse de valores econômicos, de poder e de prestígio que [...] são negados aos demais" (CUNHA, 1974, p.23).

Deste modo, o certificado pode funcionar como um dispositivo de seleção utilizado pelas empresas tendo em vista que "há uma hierarquia rígida de cargos definidos aos quais os candidatos se apresentam em fila, com seus títulos escolares, e a gerência escolhe os mais credenciados" (SALM, 1980, p.50). Braverman (1987) acrescenta que uma maior oferta de indivíduos com formação superior, faz com que esta formação seja adotada como critério de diferenciação entre os postulantes a determinada vaga de emprego. Sobre os cursos de pósgraduação, Cunha (1974) complementa que estes pertencem a um processo de diferenciação vertical, discriminando os que possuem tal titulação dos que não a possuem.

Sob esta argumentação, a pós-graduação serve ao trabalhador que pretende entrar no mercado de trabalho, unicamente por oferecer uma credencial, materializada em um certificado, de que determinado nível de escolaridade foi alcançado. As instituições de ensino, então, podem ser vistas apenas como fornecedoras de credenciais. Tal processo pode ser percebido em recente pesquisa de Cruz e Wood Jr (2014) na qual os autores apontam que o valor do curso do MBA, segundo o aluno, é dado pela possibilidade de obtenção de uma credencial e de uma marca específica no currículo. Para os autores, a chancela no currículo pode advir da marca do MBA ou da instituição na qual a pós-graduação é cursada. Em ambos os casos, parte do valor atribuído ao curso é fruto da credencial alcançada por meio do diploma obtido.

O MBA fornece, então, apenas uma credencial capaz de facilitar a relação entre empregador e empregado (BARUCH e PEIPERL, 2000). Segundo as autoras, devido a sua raridade, a pósgraduação é uma garantia de emprego aos que concluem o curso e por isso tornou-se quase prérequisito para alguns cargos gerenciais, o que resulta no aumento da demanda por cursos de pós-graduação que possam oferecer uma chancela no currículo do trabalhador. Diante da popularização do ensino superior, o trabalhador busca novas formas de se destacar e, em termos técnico-educacionais, recorre aos cursos de pós-graduação para isso. A pós-graduação possui, como desdobramento, a função social de reestabelecer o valor econômico e simbólico do certificado através da diferenciação entre os que o possuem e os que não o possuem (CUNHA, 1974).

Por isso procura afastar-se constantemente da massificação, buscando manter a raridade que confere ao seu certificado um valor econômico (habilitando o portador a disputar vagas no mercado) e simbólico (garantindo mais prestígio e status ao portador). 
Contudo, este processo intensifica a busca pela diferenciação por meio de novos cursos e do prolongamento do ensino, em vista de manter a raridade do nível de escolaridade. A cada nova modalidade de pós-graduação que se populariza - ou seja, perde sua raridade - surgem novos cursos "mais avançados". Como consequência, o movimento em busca de certificação se reinicia. Considerando essas novas certificações, Salm (1980, p.52) argumenta que:

\begin{abstract}
"antes [...] o primário formava o operário e o secundário, a gerência. Com a expansão das matrículas o secundário agora forma os operários, transferindo para os graus mais elevados a formação gerencial. A própria universidade vai deixando de ser a instância máxima para a formação das elites, assim como para a reflexão crítica, e transforma-se num mero terceiro grau de ensino [...] $\mathrm{Na}$ realidade, não se requer mais educação. Apenas, maior permanência na escola".
\end{abstract}

Este processo também pode ser percebido no trabalho de Cruz e Wood Jr (2014) que apontam que a opção por uma pós-graduação stricto sensu não é feita pelo conteúdo ou conhecimento adquirido, mas pela possibilidade de incluir o título de mestre ao currículo profissional. Tal título é um selo que qualificaria o aluno uma vez que "ser stricto sensu é um diferencial, principalmente no Brasil, onde a gente tem a banalização total da sigla MBA" (CRUZ e WOOD JR, 2014, p.35).

Percebe-se, assim, que a extensão da escolaridade visa ofertar diferenciação através de diversas modalidades de pós-graduação. Diante da "banalização" do MBA, os profissionais recorrem aos cursos de pós-graduação stricto sensu, o que influencia a formação de mestres no Brasil. Festinalli (2005) aponta que grande parte dos egressos do mestrado acadêmico se direcionava ao mercado ao invés da academia e docência, conforme esperado. Ao mesmo tempo, com o objetivo de atender esta demanda, a própria pós-graduação stricto sensu por meio torna-se mais flexível a partir da criação do mestrado profissional.

Desta forma, pode-se argumentar que o diploma de pós-graduação como critério de seleção e, principalmente, sua constante busca por diferenciação, encobrem o caráter discriminatório deste tipo de certificação. 0 acesso aos níveis educacionais mais altos não está disponível a toda população e o acesso às melhores escolas, capazes de oferecer os melhores diplomas (os mais aceitos pelo mercado), privilegia apenas uma pequena camada da população (MOTTA, 1986). Ou seja, apenas uma elite frequenta as escolas que melhor adéquam seus alunos ao mercado de trabalho. Assim, a ideia de que o acesso às escolas de elite está disponível de forma igual a toda população faz parte da ideologia capitalista que tenta homogeneizar as condições de acesso à educação, apregoando discursivamente que tais condições são as mesmas para todos (MOTTA, 1986).

Neste sentido, a desigualdade no acesso a determinadas instituições de ensino fortalece o caráter discriminatório da exigência de pós-graduação no mercado de trabalho. Tomando esta certificação como critério de seleção e aumentando o nível de exigência a cada massificação dos cursos, a elite empresarial privilegia a camada da população portadora destes certificados, excluindo do mercado de trabalho todos aqueles não dotados de tal certificação. A discriminação inicia-se nos processos seletivos para este tipo de curso, comumente baseados em cartas de recomendação e entrevistas que, por não serem institucionalizadas, não constituem um mecanismo de disputa plenamente imprevisível (CUNHA, 1974). Assim, desde a seleção até a certificação, os programas de pós-graduação procuram distinguir e zelar pela manutenção de sua raridade e pelo constante reestabelecimento de seu valor simbólico e econômico.

\title{
Breve nota sobre a mídia de negócios e sua participação na cultura do management
}

De acordo com Cruz e Wood Jr (2014, p.27), a indústria do Management pode ser definida como 


\section{A Discriminação Certificada: O Discurso da Revista Você S.A. sobre a Obrigatoriedade da Pós-Graduação para Inserção no Mercado de Trabalho.}

um "conjunto de pressupostos partilhados pelas empresas e pela sociedade" e possui dentre seus quatro pilares, a mídia de negócios (composta por jornais, revistas e livros de negócios). A mídia de negócios tem como objetivo informar o executivo sobre as principais novidades e mudanças no mercado, servindo como instrumento pelo qual a ideologia dominante do capitalismo permeia suas ideias e fornecendo legitimidade de pensamento aos jornalistas e pesquisadores (BOLTANSKI e CHIAPPELO, 2009). Como as práticas divulgadas por essas mídias são adotadas pelas empresas e aceitas no meio social, seu discurso confirma e supervaloriza o modelo liberal, que necessita de indivíduos comprometidos com esta ideologia (SIQUEIRA e FREITAS, 2006).

Nesta mesma direção, Wood Jr (2001) argumenta que a mídia de negócios no Brasil (mais especificamente as revistas de negócios) elenca temas que são abordados de forma repetida e monótona, sendo raros os artigos mais analíticos e profundos. Ao mesmo tempo, o autor prossegue afirmando que, apesar de não haver censura explícita, a necessidade de atender aos anunciantes torna as abordagens mais críticas às práticas do management desaconselháveis. Isto é, busca-se sempre manter o clima de cordial sedução entre o mundo empresarial e a imprensa especializada (WOOD JR, 2001). Isso evidencia a ambiguidade à qual as mídias de negócios se sujeitam já que, inseridas em um ambiente capitalista, precisam, corresponder à função social de informação e, ao mesmo tempo concorrer com outras empresas por anúncios e publicidade (CHARAUDEAU, 2012). Assim, para este autor, as mídias recorrem à sedução do leitor em detrimento da credibilidade que lhe seria esperada para atender ao cidadão. Deste modo, a escolha das agendas (e pautas) dessas revistas busca atender a públicos específicos de anunciantes e ao mercado empresarial (CHARAUDEAU, 2012). Enfim, esta questão ganha importância na medida em que essas mídias têm papel preponderante na construção da rotina empresarial (SIQUEIRA e FREITAS, 2006). Ou seja, atendendo a interesses específicos, a mídia de negócios oferta as "melhores práticas" de gestão para executivos ansiosos, ávidos por soluções imediatas, histórias e receitas de sucesso que possam aplacar a insegurança (WOOD JR, 2001).

\section{Metodologia}

Pesquisa de cunho qualitativo, para a construção do corpo de dados, foram coletadas as matérias publicadas em 70 edições da revista Você S.A. entre março de 2008 e dezembro de 2013. Após a leitura do título e subtítulo, a reportagem foi selecionada ou excluída de acordo com sua adequação ao tema pesquisado, através do julgamento dos pesquisadores. No total foram coletadas 102 reportagens. De forma a embasar e conduzir os protocolos metodológicos requeridos, a análise dos resultados teve como orientação metodológica a análise crítica do discurso (ACD). Mais especificamente, a análise teve como base o modelo tridimensional de Norman Fairclough (2001), que contempla as dimensões da (1) análise textual, (2) análise da prática discursiva e (3) análise da prática social. $\mathrm{Na}$ análise textual foram identificadas as metáforas, as transitividades, as modalidades, o controle interacional e o ethos (atores sociais) e, na prática discursiva, a força dos enunciados, a intertextualidade e a interdiscursividade.

\section{Análise dos Resultados}

A análise das reportagens selecionadas evidenciou que o discurso da Você S.A. sobre a necessidade de pós-graduação é pautado em dois principais aspectos: (1) a necessidade de manter o conhecimento atualizado; e (2) o posicionamento da pós-graduação como ferramenta de diferenciação capaz de inserir e promover o indivíduo no mercado de trabalho, como se pode identificar nas duas passagens a seguir:

"A base teórica é relativa à formação obtida na faculdade que o profissional cursou e precisa ser consistente. Esse conhecimento carece de atualização constante ao longo da carreira" (Como ser 


\section{Marcelo Almeida de Carvalhos Silva, Alessandra de Sá Mello Costa e \\ Ana Heloisa da Costa Lemos}

um profissional capaz de encantar as empresas?, 2013).

"A psicóloga Tatiana Lorenzi, (...), diretora de desenvolvimento humano e organizacional da Tivit, (...), fez primeiro MBA em gestão de relacionamento com clientes no Ibmec, um curso voltado para uma área operacional, com o objetivo de entender melhor o negócio da empresa. [...] Em 2010, resolveu iniciar outro MBA, agora em recursos humanos, pela FIA, para se preparar para novos desafios e avançar ainda mais na carreira. No fim de 2011, foi promovida ao cargo de principal executiva da área de gestão de pessoas da Tivit. Para quem pretende iniciar nesse segmento, recomenda-se um curso de especialização que foque em gestão de pessoas" ( 0 novo profissional, 2012).

\section{A primeira dimensão do modelo tridimensional: Análise textual}

Por meio da análise textual procuramos expor como a revista Você S.A. utiliza metáforas, transitividade, modalização, coesão e estrutura textual como formas de constituir o discurso que torna a pós-graduação requisito elementar para a entrada, permanência e ascensão do indivíduo no mercado empresarial.

As reportagens analisadas recorrem ao uso de metáforas com o objetivo de construir um ambiente corporativo hostil, no qual o trabalhador deve estar em constante atualização. As supostas mudanças frequentes do mercado e a obsolescência que trazem ao indivíduo são abordadas como inevitáveis, servindo como instrumento de pressão ao trabalhador. 0 discurso analisado procura incutir no leitor a sensação de constante obsolescência em relação a seus conhecimentos, reforçando, assim, a suposta necessidade de atualização. 0 exemplo abaixo destaca o possível aspecto negativo de não estar em dia com as novidades do mercado:

"Como não se tornar um dinossauro de escritório. O medo de ficar ultrapassado angustia muitos
profissionais. Veja o que fazer para não cair nessa armadilha. [...] Como ocorre com produtos que
ficam velhos logo após o lançamento, alguns profissionais começam a se preocupar em evitar a
obsolescência antes mesmo de amadurecer." (Como não se tornar um dinossauro de escritório,
2013). A própria escolha da palavra dinossauro ao invés de "obsoleto" demonstra como a metáfora é utilizada pela revista na tentativa de enfatizar a obsolescência como característica ameaçadora para o trabalhador.

Com relação à gramática, Fairclough (2001) aponta que a transitividade permite ao produtor textual utilizar o agente da frase de forma a omitir ou destacar a causalidade e a responsabilidade pela ação. Frequentemente, o leitor é colocado como agente das orações, em uma tentativa de impeli-lo a buscar uma alteração de sua condição atual e procurar adequar-se ao que o texto julga ser importante. Essa forma compõe a maioria das recomendações de aperfeiçoamento nas quais o leitor (referido pelo pronome "você") é o agente implícito da oração. Isso sugere uma capacidade voluntária do leitor comandar seu próprio destino e, principalmente, sugere que o profissional é o agente responsável por sua qualificação:

\footnotetext{
“Como todo mundo faz MBA, o nível técnico dos profissionais está muito parecido. [...] Se você não tem dinheiro ou não está preparado para um MBA ou mestrado, uma alternativa são os cursos de curta duração, focados em áreas específicas. Se você tem dinheiro e se julga pronto para o MBA, vá em frente. Tome cuidado para selecionar uma escola de ponta" (Educação executiva dentro da empresa, 2008).
}

Esta estratégia de direcionar o texto ao leitor torna possível a identificação do ator social denominado profissional-leitor. 0 ator social é caracterizado por sua constante inserção no discurso e é posicionado como apto a realizar grandes mudanças em sua carreira sempre que o mercado assim o demandar.

Além disto, a análise revelou a pouca modalização do texto como uma tentativa de transformar informações e eventos complexos em fatos supostamente incontestáveis. Para Fairclough 


\section{A Discriminação Certificada: O Discurso da Revista Você S.A. sobre a Obrigatoriedade da Pós-Graduação para Inserção no Mercado de Trabalho.}

(2001), isto é possível por meio de afirmações categóricas, que revelam uma opção pouco dialógica e podem levar à adoção de pressuposições. Nos exemplos abaixo, a revista afirma categoricamente o diferencial do MBA na carreira para reforçar a obrigatoriedade deste curso:

\footnotetext{
"Quando a pessoa já tem pelo menos quatro anos de atividade e possui experiência profissional em outras áreas, o ideal é um MBA para que ela consiga manter discussões de negócios dentro da companhia e abrir a possibilidade de trabalhar elementos que não são apenas focados em recursos humanos". (O novo profissional, 2012).
}

“[...] Para outras funções, a falta de idioma estrangeiro ou pós é inadmissível. Fica o recado: invista continuamente em sua formação". (Sinais de alerta, 2008).

No exemplo seguinte não há modalização sobre a valorização do mestrado profissional pelas empresas. A reportagem poderia descrever que o mestrado profissional "pode ser valorizado" ou "começa a ser mais valorizado", contudo, a reportagem é categórica em afirmar a valorização desta especialização pelas empresas. Da mesma forma, a fala do entrevistado visa não deixar dúvidas sobre a consequência do mestrado na carreira do profissional:

\footnotetext{
"Mestrado profissional já é valorizado pelas empresas [...] "Eu já fiz outras pósgraduações, mas percebo que o mestrado está totalmente ligado a meu trabalho e vai me colocar em um degrau acima na carreira", afirma Gustavo". (Mestrado profissional já é valorizado pelas empresas, 2013).
}

O exemplo acima evidencia também o profissional bem-sucedido como outro ator social identificado nas reportagens analisadas. 0 discurso analisado constrói esse ator social como um modelo para o profissional-leitor. Para isso, utiliza o testemunho do profissional bem sucedido como exemplo de quem utilizou as aplicações recomendadas pela reportagem, aplicações que resultaram em um suposto sucesso na carreira profissional. Em seu estudo sobre o discurso publicitário e das mídias, Charaudeau (2012) nos mostra que o efeito de testemunho utiliza pessoas comuns do universo da reportagem para oferecer uma palavra testemunhal. Neste caso, a revista ganha credibilidade, pois, "a declaração relatada se reveste de um caráter de veracidade por ter como única finalidade descrever a realidade tal como foi vista e ouvida" (CHARAUDEAU, 2012, p.170).

Este ator social é sempre nomeado nas matérias analisadas - visando uma valorização da sua identidade - e posicionado em relação à carreira, com destaque para o cargo e, muitas vezes, para a idade, sugerindo uma ascensão precoce. 0 testemunho deste profissional é recorrentemente convocado pela revista com o objetivo de ratificar a argumentação da reportagem. No exemplo abaixo, a profissional reforça a importância do MBA e da instituição de ensino para o sucesso na carreira:

\footnotetext{
"Walquiria Nakano, gerente jurídica da área de negócios da Votorantim Metais: "Como sou advogada, busquei os conhecimentos de administração que faltavam. Consegui entender melhor a companhia." Onde fez MBA: Fundação Instituto de Administração, FIA (São Paulo)" (O que aprendi no MBA, 2013).
}

As maneiras como os atores sociais são representados nos textos, podem indicar posicionamentos ideológicos dos produtores do texto (RESENDE E RAMALHO, 2006). Além disso, a própria escolha destes atores (em detrimento de outros) indica um posicionamento ideológico a respeito do controle interacional do produtor do texto.

Segundo Van Dijk (2008), a seleção sobre o que vai ser noticiado privilegia pessoas, organizações e países da elite e, como consequência, reconhece e legitima o poder dessa elite. Dessa forma, a análise do controle interacional torna-se pertinente na tentativa de identificar os responsáveis pela produção textual e conjecturar a respeito de suas orientações ideológicas. Por ser uma mídia de massa, a participação do leitor na definição da agenda é limitada, sem que 


\section{Marcelo Almeida de Carvalhos Silva, Alessandra de Sá Mello Costa e \\ Ana Heloisa da Costa Lemos}

possua qualquer decisão na escolha de tópicos. A determinação de temas, de entrevistados e de histórias narradas cabe apenas ao corpo editorial da revista. 0 acesso à produção textual é restrito a esse pequeno grupo de editores e jornalistas. Assim, o texto da Você S.A. desenvolve sua autonomia, não só como reprodutor das estruturas sociais, mas também como parte desta estrutura que ajuda a manter.

\section{A segunda dimensão do modelo tridimensional: A prática discursiva}

A prática discursiva envolve, segundo Fairclough (2001), os processos de produção, distribuição e consumo dos discursos. Para dar conta da produção textual, faz-se necessário uma descrição mais detalhada de quem produz o discurso em análise.

A revista Você S.A. faz parte do grupo Abril que concentra seus negócios em mídia, gráfica e distribuição, configurando-se como um dos maiores e mais influentes grupos de comunicação da América Latinai. Considerando as três atividades (mídia, gráfica e distribuição) o grupo Abril apresentou uma receita líquida de aproximadamente $\mathrm{R} \$ 3$ bilhões (R $\$ 2.975 .469$ ) dos quais 34,5\% (Aproximadamente $\mathrm{R} \$ 1.026 .536,81$ ) originaram-se de publicidade. Em 2013 a Editora Abril passou por reestruturação que, segundo o seu sítio eletrônico, objetivou manter sua posição de liderança no setor brasileiro e adaptar o grupo aos novos desafios que a indústria da comunicação enfrenta. Atualmente a Editora possui um portfólio de aproximadamente 150 títulos dentre os quais estão seis das dez revistas mais lidas no Brasil (por exemplo: Veja, Escola, Claudia, Caras e Nova).

Dentre esses títulos está a revista Você S.A. que se autodenomina como a primeira e única "publicação totalmente dedicada a ajudar executivos brasileiros a cuidar da sua carreira", cujo "cardápio editorial mensal traz reportagens muito práticas sobre o dia a dia no mercado de trabalho, apresentando temas essenciais para uma carreira bem-sucedida"ii. A origem da Você S. A. remonta ao ano de 1998 como uma extensão da revista Exame cujas vendas aumentavam sempre que suas reportagens tratavam de administração de carreiras, trajetória e qualificação profissional (WOOD JR e PAULA, 2006). Como consequência, a revista Você S. A. foi lançada buscando atingir especialmente o público dos profissionais brasileiros "interessados em aumentar sua competitividade no mercado de trabalho" (FLACH, GRISCI, SILVA e MANFREDINI, 2009).

O sucesso de vendas da revista Você S. A. é, na visão de seus editores, devido ao "perfil de instrumento de autoajuda em um contexto no qual as pessoas buscam padrões de comportamento" (WOOD JR e PAULA, 2006, p.98). A fim de suprir deficiências de conhecimento, uma vez que a equipe de redatores não é formada por administradores, são utilizados muitos manuais de referência, textos resumidos e ideias oriundas de revistas estrangeiras, livros, matérias de jornal, TV, consultores, pesquisadores, conversas e almoços com especialistas (WOOD JR e PAULA, 2006).

A Você S. A. utiliza predominantemente linguagem informal, de caráter instrumental com reportagens sintetizadas e de fácil assimilação (OLTRAMARI, FRIDERICHS e REMOR, 2013). Seu projeto gráfico busca divulgar a informação de maneira bem acessível, por meio de tópicos numerados - quase sempre com menos de 10 itens - boxes explicativos, testes, figuras (WOOD JR e PAULA, 2006; OLTRAMARI, FRIDERICHS e REMOR, 2013). Outro recurso utilizado pela revista é a tentativa de chamar a atenção com o uso de diversas cores e tipos de letras diferentes. Além disso, para ilustrar o conteúdo da matéria, as reportagens contam também com fotografias quase sempre cômicas ou caricatas, de profissionais sorridentes, bem vestidos em uma tentativa de mostrar um suposto sucesso profissional.

Destinado aos interessados em anunciar na revista, o documento chamado "Mídia Kit", descreve 


\title{
A Discriminação Certificada: O Discurso da Revista Você S.A. sobre a Obrigatoriedade da Pós-Graduação para Inserção no Mercado de Trabalho.
}

a estrutura da revista como divida nas seguintes seções: (a) mercado, (b) carreira, (c) dinheiro, (d) artigos e (e) etc. A seção mercado objetiva-se a divulgar cenários sobre o mercado de trabalho em geral com entrevistas de homens e mulheres de negócios, enquanto a seção carreira procura "mostrar ao leitor a administração da própria carreira como quem dirige uma empresa. Comportamentos, atitudes e ferramentas para o crescimento profissional e relações interpessoais". Além dessas as seções a revista traz ainda a uma parte destinada as cartas dos leitores e a seção intitulada "Agora" que traz as atualizações do mercado. Segundo o documento, a revista conta com uma tiragem média de 132 mil exemplares por mês, dos quais $77 \%$ são assinantes. 0 perfil do leitor é dividido entre homes e mulheres (51\% e 49\% respectivamente), com 82\% dos leitores está entre 20 e 39 anos. Ainda segundo o portal, 81\% dos leitores pertencem às classes A ou B e 82\% possuem curso superior completo. Os leitores da revista são, segundo o documento, profissionais com forte presença no mercado em busca de crescimento profissional e dispostos a investir em si mesmos. Estes profissionais buscam desafios, satisfação no trabalho e são ambiciosos e determinados sobre seu futuro profissional.

Na continuidade da análise da prática discursiva foram investigados os atos de fala, ou seja, as promessas e ameaças que são feitas no texto da Você S.A. As promessas surgem principalmente na voz dos profissionais bem sucedidos (explicados anteriormente):

\footnotetext{
“O paulistano Alexander Cássio Falcão Novo [...] sonhava em trabalhar numa multinacional. Ele investiu em pós-graduação de gestão empresarial, cursos rápidos de comunicação e negociação. [...]. O resultado? Alexander conseguiu subir de supervisor de produção para chefe de logística na Ambev" (Profissões mais estratégicas, 2008).
}

O exemplo acima sugere que a promoção do profissional foi resultado direto de seu investimento na pós-graduação. As promessas possuem uma relação de causa e efeito implícita entre a obtenção da certificação e a entrada ou ascensão no mercado de trabalho:

\begin{abstract}
“[...] as certificações ainda são uma importante porta de entrada para quem quiser ingressar nessa carreira. [...] Há diferentes níveis e modalidades, com diversas entidades certificadoras no mercado. [...] uma certificação pode representar um aumento imediato de até 2.000 reais no salário do profissional e ainda tem o potencial de abrir novas portas. [...]" (Todo mundo quer contratar gerentes de projeto, 2013).
\end{abstract}

Como visto, outra forma de promessa frequentemente utilizada pelas reportagens da Você S.A. é a associação do curso de pós-graduação com o retorno financeiro. A lógica capitalista afasta o trabalho de seu sentido original, transformando-o apenas em um modo de ganhar um salário, de "ganhar a vida". Neste sentido, o discurso das reportagens analisadas aproxima-se de tal ideologia, uma vez que procura associar constantemente o investimento educacional ao ganho financeiro. É também com base na remuneração que a revista justifica a escolha do que o indivíduo deve aprender:

"No Brasil, as pessoas com curso superior ganham pelo menos $20 \%$ a mais do que as pessoas que não tem diploma. Já um MBA no exterior pode dobrar o salário de um executivo em cinco anos" (A evolução é o caminho, 2009).

A remuneração, segundo as reportagens analisadas, pode ser determinante também na decisão de realizar ou não o MBA, mestrado ou outros cursos. De acordo com o exemplo abaixo, a vantagem de fazer mestrado não está associada ao conhecimento adquirido ou a seu valor social, mas sim à possibilidade de aumentar a remuneração:

"A começar pelo salário dos mestres, que, em média, é $84 \%$ mais alto do que o de trabalhadores que têm apenas a graduação, de acordo com estudo divulgado em abril de 2013 [...]." (Mestrado profissional já é valorizado pelas empresas, 2013).

As ameaças estão presentes na estratégia de convencer o profissional-leitor sobre a rapidez das mudanças ambientais e a premência de atualizações. De forma similar às promessas, as ameaças 


\title{
Marcelo Almeida de Carvalhos Silva, Alessandra de Sá Mello Costa e \\ Ana Heloisa da Costa Lemos
}

também utilizam atores sociais para legitimar sua argumentação. Contudo, dessa vez, a revista recorre ao ator social representado por professores e pesquisadores, para atestar a competitividade do mercado como ameaça à estabilidade do trabalhador:

\footnotetext{
““O mercado está mais exigente, e mesmo as pessoas competentes estão sendo demitidas", diz Yvete Piha Lehman, professora do Departamento de Psicologia Social e do Trabalho da Universidade de São Paulo. "Isso tudo gera uma ansiedade no profissional e uma pressão para que ele se mantenha inteirado o tempo todo."' (Como não se tornar um dinossauro de escritório, 2013).
}

A revista recorre também a profissionais de recursos humanos (também chamados de consultores e headhunters) para confirmar sua argumentação a respeito da importância da atualização por meio da formação continuada e da escolha da instituição de ensino, inclusive legitimando a injustiça do mercado em relação a distribuição das oportunidades:

\begin{abstract}
"Há dez meses na Gol, a executiva sabe que não pode parar de investir na carreira se quiser alcançar outros patamares. Seu plano é começar o mestrado em 2013. [...]."Vou fazer a prova [...] que permite prestar provas em instituições de mais peso, como PUC, USP e FGV", completa Andresa. (O novo profissional, 2012).

"Da mesma forma, cursar um MBA numa escola mediana não representa um diferencial competitivo. "Para um headhunter, chamam a atenção os currículos de quem [...] fez graduação ou pós em faculdades renomadas", diz Paulo Pontes, presidente da Michael Page, empresa de recrutamento [...]. Em outras palavras, o mercado é injusto porque privilegia quem teve acesso a melhores oportunidades." (0 mito do profissional perfeito, 2011).
\end{abstract}

Segundo Fairclough (2001), avaliar a força de um enunciado depende da compreensão do seu contexto, por isso, ao tratarmos da força das ameaças contidas no texto, é importante ressaltar que isso ocorre em um contexto construído com supostas transformações e incertezas, atribuindo ao indivíduo o sentimento de insegurança.

Ainda dentro do modelo tridimensional, outro aspecto da prática discursiva refere-se à análise da intertextualidade, ou seja, aos outros textos que atravessam o texto da Você S.A. Essa análise indicou que as reportagens são de natureza coletiva e permeada por diversos exemplos de intertextualidade manifesta, onde os textos que atravessam o texto principal estão explícitos no texto analisado seja por meio de citação direta ou por meio de pressuposições. Assim, a identificação da intertextualidade manifesta ocorre, predominantemente, pelo uso de aspas:

"Rodrigo Caserta. Vice-Presidente de estratégia de mercado da Totvs, empresa de TI: "[...] Quem cursou MBA nos Estados Unidos ou Europa ganha pontos - demonstra que se preparou e foi dedicado"'”. (Qualificação: o que é isso?, 2010).

Apesar de não ser um pesquisador da linha de Análise Crítica do Discurso, Maingueneau (1987), também se interessa pelo tema da intertextualidade (de uma forma geral) e da intertextualidade manifesta. Para este autor, o uso de aspas pode indicar um afastamento do locutor (neste caso, a revista) em relação ao que é dito entre aspas. Dessa forma, o produtor textual pode sustentar ou proteger sua própria posição. Por isso, é importante ressaltar que as intertextualidades citadas servem também como legitimação, pois o produtor do texto dá voz a supostas autoridades em determinados assuntos, que corroboram o argumento do discurso exposto nas reportagens. No exemplo abaixo, o ator social - o profissional bem sucedido - recebe ares de autoridade ao se explicitar o seu cargo:

"Francisco Valim, CEO da Viavarejo. "A imersão no MBA fora do país me deu uma experiência cultural. [...] Também comecei a usar ferramentas mais sofisticadas de tomadas de decisão, como modelos matemáticos e estatísticos."” (O que aprendi no MBA, 2013).

Contudo, um ator social só é reconhecido como autoridade em uma formação discursiva 


\title{
A Discriminação Certificada: O Discurso da Revista Você S.A. sobre a Obrigatoriedade da \\ Pós-Graduação para Inserção no Mercado de Trabalho.
}

específica. 0 discurso da Você S.A. procura constituir os headhunters e consultores como autoridades do ambiente empresarial, trazidos como atores sociais que legitimam o discurso da revista:

\begin{abstract}
"Dentro do universo dos mestrados, uma categoria específica - o mestrado profissional - tem se tornado um tipo de pós-graduação mais rica que os MBAs brasileiros nos últimos anos. "O MBA é superficial e, por estar muito disseminado no mercado, deixou de ser diferencial na contratação", afirma Helena Magalhães, diretora do escritório do Rio de Janeiro da Fesa, empresa de seleção de executivos." (Mestrado profissional já é valorizado pelas empresas, 2013).
\end{abstract}

O exemplo acima evidencia o possível esgotamento do MBA como certificação diferenciadora e a constituição do mestrado profissional como o curso capaz de diferenciar o profissional e manter a raridade da certificação da pós-graduação. Essa posição é reiterada nas passagens seguintes:

“[...] Por ser stricto sensu, [...], o mestrado profissional tem peso maior que um MBA, que equivale a uma especialização no Brasil." (Mestrado profissional já é valorizado pelas empresas, 2013).

"Mestrado e doutorado na área são caminhos naturais para o especialista. Outra cobrança é por atualização constante com o mercado" (Não quero ser chefe, 2009).

Outro tipo de intertextualidade manifesta é a pressuposição. Segundo Fairclough (2001), a pressuposição pode conter um efeito insincero, capaz de manipular as pessoas devido à dificuldade em contestar sua veracidade. No exemplo a seguir a pressuposição é utilizada para confirmar a existência de determinado fenômeno:

\footnotetext{
"Nos últimos anos, a pressão para inovar e a dificuldade de encontrar profissionais altamente qualificados fizeram com que as empresas voltassem a atenção para o mundo acadêmico". (Empresas buscam mestres e doutores para inovar mais, 2013).
}

O uso do artigo definido "a" para indicar "a pressão" e "a dificuldade" revela as pressuposições existentes no texto da Você S.A. Não há indícios, além das afirmativas, que indiquem a existência de pressão por inovação ou dificuldade, mas a estrutura da frase deixa a cargo do leitor a interpretação a respeito da origem desses fenômenos. Da forma como é utilizada a pressuposição procura não deixar dúvidas sobre sua argumentação. 0 discurso das matérias analisadas utiliza essa estratégia para fundamentar sua retórica sobre o mercado de trabalho.

A intertextualidade constitutiva - ou interdiscursividade - diz respeito aos discursos (e não aos textos como na intertextualidade manifesta) que atravessam o discurso principal do texto. Foram identificados dois principais discursos que permeiam o discurso da Você S.A. 0 primeiro foi o discurso publicitário que, por meio de promessas, oferece soluções para problemas (muitas vezes criados pela própria revista), que só será utilizada pelo leitor caso este se aproprie do que lhe foi recomendado (no caso, os cursos de pós-graduação).

Em relação ao discurso publicitário, o seu objetivo é seduzir o leitor para que o produtor textual consiga persuadi-lo a agir do modo desejado (CHARAUDEAU, 2010). Desta forma, o discurso publicitário, ao mesmo tempo em que apresenta o objeto de desejo (vaga de emprego ou promoção) como benefício, apresenta também o produto (cursos de pós-graduação) como o "único meio [...] para realizar o sonho" (CHARAUDEAU, 2010, p.64). No caso da Você S.A., são oferecidas recomendações de pós-graduações, ofertadas como forma de satisfazer uma demanda criada pela própria revista.

Essa dinâmica é ilustrada no exemplo abaixo, no qual a evolução na carreira é colocada como um objeto de desejo que pode ser alcançado através do consumo do produto: o investimento em pós-graduação: 
"Uma boa forma de crescer durante a crise é investir na educação e antecipar o plano de fazer uma pós-graduação ou um curso técnico." (Sua nova estratégia de carreira, 2009).

O discurso publicitário fica mais evidente no exemplo abaixo, em que a reportagem apresenta o problema (rápida mudança no ambiente, mudanças frequentes) e oferece a solução (se atualizar permanentemente) aos que pretendem ter sucesso no mercado:

“[...] as empresas e os negócios vivem um período de mudanças frequentes, no qual a bagagem de conhecimento que um profissional acumula na carreira nem sempre dá conta [...]. A saída, então, é [...] atualização permanente, tentando dominar as novidades e as tendências do mercado e da profissão" (Aprender rápido é uma competência valorizada, 2010).

O segundo discurso identificado, se aproxima do discurso capitalista e foi denominado discurso do mercado. Este ressalta a importância da competitividade, individualidade, ambição e mercantilização das escolhas, que passam a ser embasadas pela promessa de retorno financeiro. No exemplo seguinte podemos perceber as características do discurso publicitário (oferta do mestrado como solução dos problemas) e do discurso de mercado (o mestrado profissional é posicionado como capaz de oferecer promoção e aumento salarial como prova de sucesso):

“[...] o dono de um título de mestre profissional tem remuneração $37 \%$ mais alta que a de um mestre. Entre alunos do [...] (Insper), de São Paulo, 60\% dos alunos obtiveram aumento salarial ou promoção após a conclusão do mestrado profissional. Outros $40 \%$ foram promovidos [...]." (Mestrado profissional já é valorizado pelas empresas, 2013).

\section{A terceira dimensão do modelo tridimensional: Prática Social}

A análise do discurso como prática social torna possível identificar que a Você S.A. produz um discurso que tenta legitimar a pós-graduação como exigência para entrada, permanência e ascensão do trabalhador no mercado de trabalho. Como consequência da disseminação deste discurso, percebe-se um aumento na oferta e demanda de cursos de MBA e mestrado, especialmente no caso do mestrado profissional.

A disseminação deste discurso torna o título (e o diploma) de pós-graduação comum e, por isso, permite que empregadores façam exigências maiores aos candidatos a uma vaga de trabalho, não por uma real necessidade que o cargo exigiria, mas apenas pela maior oferta de pessoas com algum tipo de certificação. Ou seja, em função de uma maior quantidade no número de pósgraduados, os empregadores percebem as certificações como dispositivo de separação, exigindo trabalhadores com qualificações acima do que seria necessário para um bom desempenho da função. Dessa forma, a necessidade de qualificação decorrente da educação formal apresenta-se como falaciosa, já que a extensão da educação perdeu sua relação com as exigências ocupacionais, representando simplesmente critério de seleção discriminatório entre os "pósgraduados" e os "sem pós-graduação".

Assim, podemos supor que o discurso da revista Você S.A. legitima esta prática de separação e exclusão, ao propagar uma suposta exigência de trabalhadores pós-graduados, que finda por excluir do mercado de trabalho a massa de trabalhadores que não obtiver tais certificações. Essa exclusão é agravada pela ênfase dada à escolha da escola na qual o curso deve ser feito. De acordo com as matérias analisadas, pode-se afirmar que as revistas de negócio no Brasil prezam por uma relação amistosa com seus anunciantes, dentre eles as instituições de ensino, que anunciam seus cursos de pós-graduação nas páginas destas revistas.

Além disso, lembrando o caráter doutrinador das escolas consideradas de elite, a recorrência de referências aos nomes das instituições de ensino, sugere que o discurso da Você S.A. adere a esta 


\section{A Discriminação Certificada: O Discurso da Revista Você S.A. sobre a Obrigatoriedade da Pós-Graduação para Inserção no Mercado de Trabalho.}

ideologia, na medida em que coloca estas instituições como "escolas de ponta" (utilizando o termo da própria revista). Percebe-se por meio da ênfase dada à escolha da instituição de ensino que o discurso da Você S.A. privilegia determinado grupo de instituições, procurando legitima-lo como a melhor escolha a ser feita pelo trabalhador. Este posicionamento também pode servir como processo discriminatório, pois além da posse ou não das certificações, o trabalhador será avaliado também pela instituição que frequentou.

Há ainda nos discursos analisados, referências ao abandono das instituições de ensino tradicionais e a adoção das escolas de negócios internas às organizações, operando mais claramente no sentido de doutrinação ideológica pela transmissão de valores da empresa. 0 discurso da Você S.A. contribui também para a reprodução e continuidade da estrutura social, uma vez que colabora para a manutenção dos trabalhadores nas condições exigidas pela divisão de trabalho capitalista. Isso exige que a classe dominante, para sustentar sua posição, exerça seu poder, mantendo a classe dominada sob seu controle. Para este fim, as instituições de ensino procuram formar indivíduos capazes de se adaptar, se submeter e aceitar as regras impostas pelas classes dominantes.

Ademais, o discurso da Você S.A. declara que o aprendizado contínuo é necessário devido às constantes mudanças do mercado e consequente obsolescência do conhecimento do trabalhador. Mezáros (2001) cita a obsolescência planejada para explicar a diminuição proposital da vida útil dos produtos para justificar o lançamento e a substituição contínua por novos produtos no mercado, fazendo girar a roda do consumo na sociedade. Parece-nos que a qualificação do trabalhador sofre processo similar. Ao sugerir um mercado em constante modificação, que exige atualizações constantes, o discurso da revista torna potencialmente obsoleto todo e qualquer trabalhador que não estiver em dia com as últimas novidades do mercado no que tange à educação formal. Isto ocorre não só para colocar a revista em lugar de destaque como transmissora de tais novidades, transformando-a em fonte supostamente confiável para o trabalhador renovar seus conhecimentos, mas principalmente para justificar a exclusão dos trabalhadores que forem considerados como não atualizados ou sem a formação desejada.

\section{Considerações Finais}

A presente pesquisa teve como objetivo descrever o discurso de uma popular revista de negócios brasileira sobre a necessidade da certificação de pós-graduação para o ingresso, permanência e ascensão no mercado de trabalho. Por meio do modelo tridimensional de Faiclough (2001) procuramos desvelar os estratagemas linguísticos utilizados pela revista, processo este que nos conduz para alguns resultados relevantes.

Em primeiro lugar, corrobora-se, por meio deste estudo, o argumento encontrado na literatura a respeito do posicionamento ideológico das mídias de negócios. Assim, os resultados encontrados indicam que o discurso da Revista Você S.A. é comprometido com discursos hegemônicos em nossa sociedade que apregoam a mobilidade social como consequência direta e natural da capacidade individual de aperfeiçoamento.

A partir disto, podemos inferir que o discurso da revista analisada é voltado para o caráter ideológico de convencer o trabalhador a buscar a pós-graduação com fins exclusivos de segregação. Considerando que apenas uma parcela populacional tem acesso às instituições consideradas de elite e aos cursos de pós-graduação que proporcionariam essa qualificação, seria razoável presumir que o restante da população estaria então fadado a vagar a margem do mercado de trabalho ou ocupando cargos precarizados como empregos temporários e terceirizados. 


\section{Marcelo Almeida de Carvalhos Silva, Alessandra de Sá Mello Costa e \\ Ana Heloisa da Costa Lemos}

Assim, o discurso da Você S.A., ao reforçar, reproduzir e legitimar a necessidade da pósgraduação e da constante atualização pode servir como justificativa para a exclusão daqueles que não obtém tais títulos.

Ao mesmo tempo, a exigência de pós-graduação e aprendizado contínuo como mecanismo de exclusão, se coaduna ao argumento de Gorz (2007) que postula que o sistema capitalista, baseado em sua lógica de acumulação, não comporta toda a massa de trabalhadores disponível e, por isso, precisa fazer uso de diversos dispositivos com o intuito de mascarar o excedente de mão de obra disponível. Estes dispositivos utilizados para diferenciar os postulantes ao mercado de trabalho materializam-se na forma de diplomas, cursos, certificados e atualizações de aprendizado e são sempre renovados e reinventados na medida em que perdem seu valor simbólico.

Admitindo tal cenário, é possível conjecturar a respeito das motivações que levam o trabalhador a buscar cursos de pós-graduação. Assim, o trabalhador lança-se em busca de cursos de pósgraduação não mais em busca do conhecimento científico e do aprendizado no processo de ensino e pesquisa, mas em busca da marca no currículo dada pelas certificações obtidas nas mais diversas instituições de ensino. Isto é, assumindo que estes cursos possuem seu valor reconhecido pela certificação, pode-se presumir que os trabalhadores-alunos assumem as instituições de ensino apenas como fornecedoras de chancelas utilizadas para melhor se alocar no mercado de trabalho.

É possível, portanto, afirmar que o discurso da revista Você S.A. ajuda na construção de uma realidade social que demanda certificações para o mercado de trabalho e, por consequência, constitui trabalhadores ávidos por certificações e atualizações cada vez mais frequentes. De forma complementar, estes indivíduos colaboram, por meio de suas práticas, na constituição do discurso hegemônico da premência da formação constante. Assim, de forma dialética, estes trabalhadores constituem e são constituídos por este discurso.

Todavia, este assunto ainda requer ampla pesquisa e discussão. Para o aprofundamento do estudo, sugerimos a diversificação das fontes de pesquisa levando em consideração outros tipos de mídia como jornais, outras revistas de negócio, além de outros formadores do discurso empresarial como empresas de recrutamento, profissionais de RH. Desta forma, seria relevante uma pesquisa junto a profissionais, recrutadores e executivos de empresas com o intuito de investigar quais valores econômico, social e simbólico o mercado atribui aos dois tipos de pósgraduação (latu sensu e stricto sensu). Um estudo desta natureza permitiria inferências a respeito da valorização ou não de um tipo de pós-graduação em detrimento da outra. Considerando novamente os quatro pilares da indústria do management, parece importante analisar o discurso das instituições de ensino sobre a necessidade de pós-graduação para inserção no mercado de trabalho, bem como seu discurso sobre a diferenciação entre os objetivos e destinos dos alunos de pós-graduação latu sensu e stricto sensu. Esta investigação permitiria discussões mais profícuas a respeito da formação do corpo docente brasileiro, haja vista o perfil do discente e sua motivação para fazer o curso de mestrado baseada apenas na expectativa de alocação no mercado de trabalho e não no interesse docente.

\section{Referências}

A EVOLUÇÃO É O CAMINHO. Você S.A., São Paulo Janeiro, 2009.

AKTOUF, O. Ensino de Administração: Por uma Pedagogia para a Mudança. Revista 0 \& S, Salvador, v.12, n.35, p.151-159, out./dez. 2005.

ALVES, G. Dimensões da Reestruturação Produtiva: ensaios de sociologia do trabalho. $2^{\text {a }}$ 
edição - Londrina: Praxis; Bauru: Canal 6, 2007.

BARBARA, M.M. Reestruturação produtiva, qualificação, requalificação e desemprego: percepção e sofrimento do trabalhador. Psicologia: ciência e profissão 19.1 (1999): 30-49.

BARTALOTTI, O.; MENEZES-FILHO, N. A. A relação entre o desempenho da carreira no mercado de trabalho e as escolha profissional dos jovens. Revista de Economia Aplicada, v.11, p. 487-506, 2007.

BARUCH, Y.; PEIPERL, M. The impact of an MBA on graduate carrers. Human Resource Management Journal, v.10, n.2, 2000.

BOltANSKI, L; CHIAPEllo, E. O Novo Espírito do Capitalismo. São Paulo: Martins Fontes, 2009.

BRAVERMAN, H. Trabalho e capital monopolista. Rio de Janeiro: Zahar, 1987.

CHARAUDEAU, P. Discurso das Mídias. São Paulo: Contexto, 2012.

CHARAUDEAU, P. 0 discurso propagandista: uma tipologia. IN: MACHADO, I. L. MELLO, R. Análises do Discurso Hoje. 2010

CIRANI, C. B. S; SILVA, H. H. M. da; CAMPANARIO, M. de A. A evolução do ensino da pósgraduação estrito senso em administração no Brasil. RAC, Curitiba , v.16, n.6, 2012 .

COMO SER UM PROFISSIONAL CAPAZ DE ENCANTAR AS EMPRESAS? Você S.A., São Paulo, Fevereiro, 2013.

CRUZ, J.F.P; WOOD JR, T, MBAs: cinco discursos em busca de uma nova Narrativa. Cadernos EBAPE.BR, v.12, n.1, Rio de Janeiro, Jan./Mar. 2014.

CUNHA, L. A pós-graduação no Brasil: função técnica e função social. RAE, 14(5), 1974

DELUIZ, N. Qualificação, competências e certificação: visão do mundo do trabalho. Formação, Brasília, v.1, n.2, p.5-15, 2001.

EDUCAÇÃO EXECUTIVA DENTRO DA EMPRESA. Você S.A., São Paulo, Setembro, 2008.

EMPRESAS BUSCAM MESTRES E DOUTORES PARA INOVAR MAIS. Você S.A., São Paulo, Junho, 2013.

FAIRCLOUGH, N. Discurso e Mudança Social. Brasília: UnB, 2001.

FERNANDES, R.; MENEZES-FILHO, N.A. Escolaridade e demanda relativa por trabalho: uma avaliação para o Brasil nas décadas de 80 e 90. In: CHAHAD, J. P.; MENEZES-FILHO, N. A. Mercado de trabalho no Brasil: salário, emprego e desemprego numa era de grandes mudanças. São Paulo: LTR, 2002.

FERREIRA, F. Os determinantes da desigualdade de renda no Brasil: luta de classes ou heterogeneidade educacional? Rio de Janeiro: PUC-Rio, fev.(Texto para discussão,415), 2000.

FESTINALLI, R.C.A Formação de Mestres em Administração: Por Onde Caminhamos? Revista 0 \& S, Salvador, v.12, n.35, p.135-150, 2005.

FOGACA, Azuete; SALM, Cláudio L.. Educação, trabalho e mercado de trabalho no Brasil. Cienc. Cult., São Paulo, v.58, n.4, 2006.

GAULEJAC, V. Gestão como Doença Social. São Paulo: Idéias \& Letras, 2007.

GORZ, A. Metamorfoses do trabalho: crítica da razão econômica. São Paulo: Annablume, 2007. 
Instituto Nacional de Estudos e Pesquisas Educacionais. Censo da Educação Superior: portal.mec.gov.br/. Acessado em 17 de abril de 2014. Brasília,2013.

KARAWEJCZYK, T.C.; SILVEIRA, A. S.; THIEL, C. B.. VELASQUES, F.V. Formação Gerencial: Para que e para quem? ENANPAD, XXXVI Rio de Janeiro, 2012.

LEITE, M. D. P. Qualificação, desemprego e empregabilidade. São Paulo em perspectiva, v.11, n.1, 64-69, 1997.

LEMOS, A. H.C., DUBEUX, V.J.C., PINTO, M.C.S. Educação, Empregabilidade e Mobilidade Social: Convergencias e Divergências. Cadernos EBAPE.BR, Rio de Janeiro, v.7, n.2. p.372-384, 2009.

MACHADO, L. Educação Básica, Empregabilidade e Competência. Trabalho \& Educação Belo Horizonte, n.03, p.15-31, jan./jul. 1998.

MAingueneAU, D. Novas Tendências Em Análise Do Discurso. 3. Ed. Campinas, São Paulo: Pontes, 1987.

MESTRADO PROFISSIONAL JÁ É VALORIZADO PELAS EMPRESAS. Você S.A., São Paulo Junho, 2013.

MÉSZÁROS, István. Para além do capital: rumo a uma teoria da transição. São Paulo: Boitempo: UNICAMP, 2002.

MORGAN, G. Paradigmas, Metáforas e Resolução de Quebra-cabeças na Teoria das Organizações. RAE, v.45, n.1, jan-mar, 2005.

MOTTA, F.C.P; Organização e poder: Empresa, Estado e Escola. São Paulo. Atlas,1986

NÃO QUERO SER CHEFE. Você S.A., São Paulo Março, 2009.

NICOLINI, A. Qual será o Futuro das Fábricas de Administradores? RAE, São Paulo, v.43, n.2, p.44-54, abr./jun. 2003.

O MITO DO PROFISSIONAL PERFEITO. Você S.A., São Paulo Outubro, 2011.

O NOVO PROFISSIONAL. Você S.A., São Paulo Fevereiro, 2012.

O QUE APRENDI NO MBA. Você S.A., São Paulo Novembro, 2013.

OLTRAMARI, A. P.; FRIDERICHS, B. P.; REMOR, G. Carreira, Família e a Dialógica do Assujeitamento: 0 Discurso Vigente de uma Revista Popular de Negócios. ENANPAD, XXXVII Rio de Janeiro, 2013.

PAIVA, V. Anos 90: as novas tarefas da educação dos adultos na América Latina. Cadernos de Pesquisa, v.89, 1994. p.29-38.

PARKER, M.; JARY, D. The McUniversity: Organizations, management, and academic subjectivity. Organization, v.2, n.2, p.319-338, 1995.

PROFISSÕES MAIS ESTRATÉGICAS. Você S.A., São Paulo Outubro, 2008.

QUALIFICAÇÃO: O QUE É ISSO? Você S.A., São Paulo Abril, 2010.

RESENDE, V. M.; RAMALHO, V. Análise de discurso crítica. São Paulo: Contexto 2006.

RUAS, R. Mestrado modalidade profissional: em busca da identidade. RAE, v.43, n.2, 2003.

SALM, C. Escola e trabalho. São Paulo: Brasiliense, 1980.

SARAIVA, L.A.S. A Educação Superior em administração no Brasil e a questão da 
emancipação: Um túnel no fim da luz? Revista G\&P, v.12, n.1, 2011.

SINAIS DE ALERTA. Você S.A., São Paulo Dezembro, 2008.

SIQUEIRA, M.V.S; FREITAS, M.E. O Papel da Mídia Especializada em Negócios na Reprodução do Discurso Organizacional em Recursos Humanos no Brasil. ENANPAD, 30, 2006, Salvador, 2006.

STURDY, A.; GABRIEL, Y. Missionaires, mercenaries or car salesmen? MBA teaching in Malaysia. Journal of Management Studies, v.37, n.7, p.979-1002, 2000.

TODO MUNDO QUER CONTRATAR GERENTES DE PROJETO. Você S.A., São Paulo Março, 2013.

VAN DIJK, T. Discurso e Poder. São Paulo. Contexto, 2008.

WOOD JR, T.; PAULA, A.P.P. A Mídia Especializada e a Cultura do Management. Revista O\&S, v.13, n.38, Jul/Set, 2006.

WOOD JR, T; PAULA, A.P.P. 0 fenômeno dos MPAs brasileiros: hibridismo, diversidade e tensões. RAE, v.44, n.1, p.116-129, 2004.

WOOD JR, T. Organizações espetaculares. Ed. FGV, 2001.

WOOD JR. T. MBA: prós e contras. Carta Capital, 26 de maio de 2013.

\footnotetext{
i Balanço do grupo Abril, disponível em: grupoabril.com.br/pt/quem-somos/balanco, acessado em 28/02/2014.

ii Você S.A. Mídia Kit, disponível em: www.publiabril.com.br/marcas/vocesa/revista/informacoes-gerais, acessado em $01 / 12 / 2013$
} 